Bull. Chem. Soc. Ethiop. 2019, 33(1), 51-60.

ISSN 1011-3924

(C) 2019 Chemical Society of Ethiopia and The Authors

Printed in Ethiopia

DOI: https://dx.doi.org/10.4314/bcse.v33i1.5

\title{
PHOTOCATALYTIC DEGRADATION OF ORGANIC DYES BY INFINITE ONE DIMENSIONAL COORDINATION POLYMER BASED ON Zn(II) IN WATER
}

\author{
Wei-Ping $\mathrm{Wu}^{1 *}$, Qiongjie Ding ${ }^{2}, \mathrm{Xi-Ren} \mathrm{Wu}^{2 *}$, Yi-Jia Huang ${ }^{2}$, Chunhua Gong ${ }^{2}$, Hui Huang ${ }^{2}$, \\ Manoj Trivedi ${ }^{3}$ and Abhinav Kumar ${ }^{4 *}$ \\ ${ }^{1}$ College of Chemistry and Environmental Engineering, Sichuan University of Science \& \\ Engineering, Zigong 643000, P. R. China \\ ${ }^{2}$ Dongguan Key Laboratory of Drug Design and Formulation Technology, Key Laboratory of \\ Research and Development of New Medical Materials of Guangdong Medical University, \\ School of Pharmacy, Guangdong Medical University, Dongguan, 523808, P. R. China \\ ${ }^{3}$ Department of Chemistry, University of Delhi, Delhi, India \\ ${ }^{4}$ Department of Chemistry, Faculty of Science, University of Lucknow, Lucknow 226 007, India
}

(Received April 15, 2018; Revised December 26, 2018; Accepted January 9, 2019)

\begin{abstract}
A new $\mathrm{d}^{10}$ based $\mathrm{Zn}(\mathrm{II})$ coordination polymer $(\mathrm{CP})$, formulated as $\left[\mathrm{Zn}\left(\mathrm{SO}_{4}\right)_{3}(\mathrm{DMF})_{3}\right]_{\mathrm{n}}(\mathbf{1})$, has been synthesized and structurally characterized. The single crystal X-ray diffraction results indicates that CP1 forms $1 \mathrm{D}$ inorganic $-\left[\mathrm{Zn}-\mathrm{SO}_{4}-\mathrm{Zn}\right]_{n}$ - chain along the $a c$ plane. The thermal stability, UV/Vis diffuse-reflection spectrum and photocatalytic behavior of 1against organic dyes have been investigated. The photocatalysis results indicate that displays better photocatalytic activities against RhBin comparison toMV. The probable mechanism associated with the photocatalysis of $\mathbf{1}$ against organic dyes has been addressed using density of states (DOS) calculations.
\end{abstract}

KEY WORDS: Zn(II), Coordination polymers, X-ray, Photocatalysis, DOS

\section{INTRODUCTION}

Currently much attention has focused on numerous harmful industrial organic pollutants that have been released into the environment and as a consequence the biosphere [1-4]. To cope-up with this problem, in recent years, many efforts of various groups worldwide have been dedicated to develop new and efficient photocatalytic materials based on coordination polymer and semiconductors with fascinating structural motifs that can convert these organic pollutants into environmentally safe species [5-6].

It had now been established that the photocatalytic decomposition of dyes had been successfully in the presence of MIL-53 [7]; $\mathrm{Fe}_{3} \mathrm{O}_{4} / \mathrm{MIL}-100(\mathrm{Fe})$ core-shell microspheres [8], ZIF-8 [9], etc. Hence, application of these MOFs in the photocatalytic decompositions of dyes revealed their great potential as photocatalysts [10]. It is well known that the electronic properties of MOFs depend on their chemical compositions and structures [11-12], viz. the nature of the organic ligands (linkers) metal ions, and metal-oxide clusters. The explanation of electronic properties of MOFs were constructed by the SBUs of metal-oxide cluster and conjugated organic linkers, which represent the discrete quantum dotanalogue the photon antenna, respectively [13].

Based on these aspects and in an attempt to investigate photo-current-generating properties of MOFs, herein, in the presented work, a new Zn-based coordination polymer, formulated as $\left[\mathrm{Zn}\left(\mathrm{SO}_{4}\right)(\mathrm{DMF})\right]_{\mathrm{n}}(\mathbf{1})$ has been synthesized and structurally characterized by single-crystal $\mathrm{X}$ -

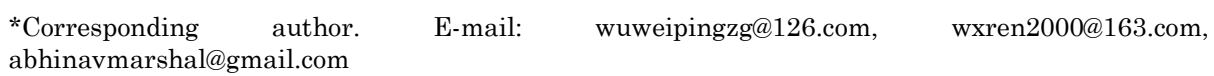

This work is licensed under the Creative Commons Attribution 4.0 International License 
ray diffraction. The UV-Vis absorption, diffuse reflectance spectra and photocatalytic behaviours have been investigated.

\section{EXPERIMENTAL}

\section{General considerations}

All the chemicals were obtained from commercial sources and used without further purification. The powder X-ray diffraction (PXRD) data was collected on Bruker D8 Advance X-ray diffractometer with $\mathrm{Cu}-\mathrm{K \alpha} \alpha$ radiation $(\lambda=1.5418 \AA)$ at $50 \mathrm{kV}, 20 \mathrm{~mA}$ with a scanning rate of $6^{\circ} \mathrm{min}$ and a step size of $0.02^{\circ}$. The simulated powder patterns for 1 was obtained using Mercury 2.0 program. The purity and homogeneity of the bulk products were assessed by comparing the simulated and experimental X-ray powder diffraction patterns. Fourier transform infrared (FT-IR) spectra as $\mathrm{KBr}$ pellet were recorded using Nicolet Impact 750 FTIR spectrometer in the range of $400-4000 \mathrm{~cm}^{-1}$. Thermogravimetric analysis (TGA) was performed under nitrogen atmosphere from room temperature to $800{ }^{\circ} \mathrm{C}$ at a heating rate of $10^{\circ} \mathrm{C} \mathrm{min}^{-1}$, using SDT Q600 thermogravimetric analyzer.

\section{X-Ray crystallography}

Single crystal X-ray diffraction data collection was carried out on Bruker Smart Apex diffractometer which was equipped with graphite monochromated $\mathrm{MoK} \alpha$ radiation $(\lambda=0.71073$ $\AA$ ) by using an $\omega$-scan technique. The intensities of the absorption effects were corrected by using SADABS. The structures were solved by direct methods (SHLEXS-2014) and refined by a full-matrix least-squares procedure based on $F^{2}$ (Shelxl-2014) [14]. All the hydrogen atoms were generated geometrically and refined isotropically using the riding model. Crystallographic details and selected bond dimensions for 1 are listed in Tables 1 and 2 (CCDC: 1816723).

Table 1. Crystal data and structure refinement for $\mathbf{1}$.

\begin{tabular}{|l|l|}
\hline Empirical formula & $\mathrm{C}_{12} \mathrm{H}_{27} \mathrm{~N}_{3} \mathrm{O}_{15} \mathrm{~S}_{3} \mathrm{Zn}_{3}$ \\
\hline Formula weight & 745.65 \\
\hline Crystal system & Orthorhombic \\
\hline Space group & $\mathrm{P}{ }_{1} 2_{1} 2_{1}$ \\
\hline $\mathrm{a} / \AA$ & $5.0627(10)$ \\
\hline $\mathrm{b} / \AA$ & $14.619(3)$ \\
\hline $\mathrm{c} / \AA$ & $32.981(7)$ \\
\hline$\alpha /{ }^{\circ}$ & 90 \\
\hline$\beta /{ }^{\circ}$ & 90 \\
\hline$\gamma /{ }^{\circ}$ & 90 \\
\hline Volume/ $\AA^{3}$ & $2441.0(8)$ \\
\hline $\mathrm{Z}$ & 4 \\
\hline$\rho_{\text {calc }} / \mathrm{cm}^{3}$ & 2.029 \\
\hline$\mu / \mathrm{mm}^{-1}$ & 3.257 \\
\hline $\mathrm{F}(000)$ & 1512 \\
\hline Index ranges & $-6 \leq \mathrm{h} \leq 6,-18 \leq \mathrm{k} \leq 18,-42 \leq 1 \leq 41$ \\
\hline Independent reflections & $19376 \mathrm{R}_{\text {int }}=0.0851, \mathrm{R}_{\text {sigma }}=0.0669$ \\
\hline Goodness-of-fit on $\mathrm{F}^{2}$ & 1.021 \\
\hline Final R indexes [I $=2 \sigma(\mathrm{I})]$ & $\mathrm{R}_{1}=0.0594, \mathrm{wR}_{2}=0.1357$ \\
\hline Final R indexes [all data] & $\mathrm{R}_{1}=0.0851, \mathrm{wR}_{2}=0.1500$ \\
\hline
\end{tabular}

Bull. Chem. Soc. Ethiop. 2019, 33(1) 
Table 2. Bond Lengths and angles for 1.

\begin{tabular}{|l|l|l|l|}
\hline Zn1A-O4 & $1.941(7)$ & Zn1A-O5 & $1.942(8)$ \\
\hline Zn1A-O3 & $1.943(8)$ & Zn1A-O3 & $1.957(7)$ \\
\hline Zn1B-O3 & $1.943(7)$ & Zn1B-O4 & $1.931(7)$ \\
\hline Zn1B-O5 & $1.947(7)$ & Zn1B-O1 & $1.948(8)$ \\
\hline
\end{tabular}

A: $-x+1 / 2,-y, z+1 / 2 ; B: x, y+1 / 2,-z+1 / 2$

Synthesis of $\left[\mathrm{Zn}\left(\mathrm{SO}_{4}\right)_{3}(\mathrm{DMF})_{3}\right]_{\mathrm{n}}(\mathbf{1})$

A mixture of 2,2'-diamino-biphenyl-4,4'-dicarboxylic acid $\left(\mathrm{H}_{2} \mathrm{~L}\right)(0.1 \mathrm{mmol}), \mathrm{ZnSO}_{4} \cdot 7 \mathrm{H}_{2} \mathrm{O}(0.2$ $\mathrm{mmol}$ ) and DMF (5 mL) was stirred for $30 \mathrm{~min}$ in air. The resulting solution was placed in a 25 $\mathrm{mL}$ vial container and heated to $105^{\circ} \mathrm{C}$ for $72 \mathrm{~h}$. After that the reaction mixture was cooled to room temperature at a rate of $2{ }^{\circ} \mathrm{C} / \mathrm{h}$. Colorless block crystals of 1 were obtained in $25 \%$ yield. IR: 3078(m); 1630(v); 1510(m); 1406(v); 1239(m); 1121(v); 779(vs); 688(m); 598(m).

\section{Photocatalytic method}

The photocatalytic reactions were performed as follows: $50 \mathrm{mg}$ of $\mathbf{1}$ were dispersed in $50 \mathrm{~mL}$ aqueous solution of $\mathrm{RhB} / \mathrm{MV}(10 \mathrm{mg} / \mathrm{L})$ under stirring in the dark for $30 \mathrm{~min}$ to ensure the establishment of an adsorption-desorption equilibrium. Then the mixed solution was exposed to UV irradiation from an $\mathrm{Hg}$ lamp $(250 \mathrm{~W})$ and kept under continuous stirring during irradiation for $100 \mathrm{~min}$. Samples of $5 \mathrm{~mL}$ were taken out every $10 \mathrm{~min}$ and collected by centrifugation for analysis by UV-Vis spectrometer. By contrast, the simple control experiment was also performed under the same condition without adding any catalysts. The photocatalytic activity studies were carried out in a Shimadzu UV-Vis 2501PC recording spectrophotometer.

\section{Computational details}

The probable mechanism associated with the photocatalytic property of $\mathbf{1}$ against organic dyes has been ascertained using density of states (DOS) and partial DOS calculations. For that the optimized molecular geometry of $\mathbf{1}$ have been computed using the B3LYP exchange-correlation functional. ${ }^{24}$ The $6-31 G^{* *}$ basis set for all the atoms were used for geometry optimization All the calculations were performed using Gaussian 09 programme [15]. GaussSum 3.1 was used to obtain density of state (DOS) plots [16].

\section{RESULTS AND DISCUSSION}

$\left[\mathrm{Zn}\left(\mathrm{SO}_{4}\right)_{3}(\mathrm{DMF})_{3}\right]_{n}(\mathbf{1})$

Single crystal X-ray diffraction analysis shows that the asymmetric unit of $\mathbf{1}$ consists of three crystallographically independent $\mathrm{Zn}$ (II) ions, three coordinated sulfate ions and three coordinated DMF molecules. The coordination environment of $\mathrm{Zn}(\mathrm{II})$ ions are shown in Figure 1a. All the $\mathrm{Zn}(\mathrm{II})$ ions are four-coordinated with three oxygen atoms from two sulfate ions and one oxygen atom from coordinated DMF molecule. Zn1A was constructed by O1A, O3A, O4A and O5A (A: -1/2+x,3/2-y,1-z), Zn1B was bonded by O3C, O1B, O4C and O5B (B: -1/2+x,3/2$\mathrm{y}, 2-\mathrm{z}$ and $\mathrm{C}: 1 / 2+\mathrm{x}, 3 / 2-\mathrm{y}, 1-\mathrm{z})$, and $\mathrm{Zn} 1 \mathrm{C}$ was linked by O2B, O3B, O5C and O1C. The Zn-O distances are in the range of 1.887(10)-2.047(8) $\AA$. The coordination geometry of $\mathrm{Zn}(\mathrm{II})$ ion is a distorted tetrahedron. The maximum deviations of $\mathrm{Zn} 1 \mathrm{~B}$ and $\mathrm{Zn} 1 \mathrm{C}$ are 0.3168 and $0.4002 \AA$ from the best least-square base plane, respectively. In compound 1, each sulfate ion adopts 
tridentate bridging mode to link the $\mathrm{Zn}$ (II) ions into $1 \mathrm{D}$ chain structure. In other words, the sulfate anions act as $\mu_{3}$-bridging monodentate/monodentate coordination fashion to bind three $\mathrm{Zn}(\mathrm{II})$ ions, forming a $1 \mathrm{D}$ inorganic- $\left[\mathrm{Zn}-\mathrm{SO}_{4}-\mathrm{Zn}\right]_{n}-$ chain subunits (Figure $1 \mathrm{~b}$ ). In the 1D chain architecture, there exist weak hydrogen bindings $\left(\mathrm{C} 1 \mathrm{~A}-\mathrm{H} 1 \mathrm{AA} \cdots \mathrm{O} 1 \mathrm{~A}=3.302(12), 145^{\circ}, \mathrm{C} 4 \mathrm{~A}-\right.$ $\mathrm{H} 4 \mathrm{AB} \cdots \mathrm{O} 4 \mathrm{C}=3.474(14), 157^{\circ}, \mathrm{C} 4 \mathrm{C}-\mathrm{H} 4 \mathrm{CB} \cdots \mathrm{O} 1 \mathrm{~B}=3.521(13), 160^{\circ}, \mathrm{C} 1 \mathrm{~B}-\mathrm{H} 1 \mathrm{BA} \cdots \mathrm{O} 1 \mathrm{~B}=$ $\left.3.276(14), 155^{\circ}\right)$ to stabilize the structure. Thus, these $1 \mathrm{D}$ chains are connected by hydrogen bonds interactions into 2D supramolecular network (Figure 2c) [17-20].

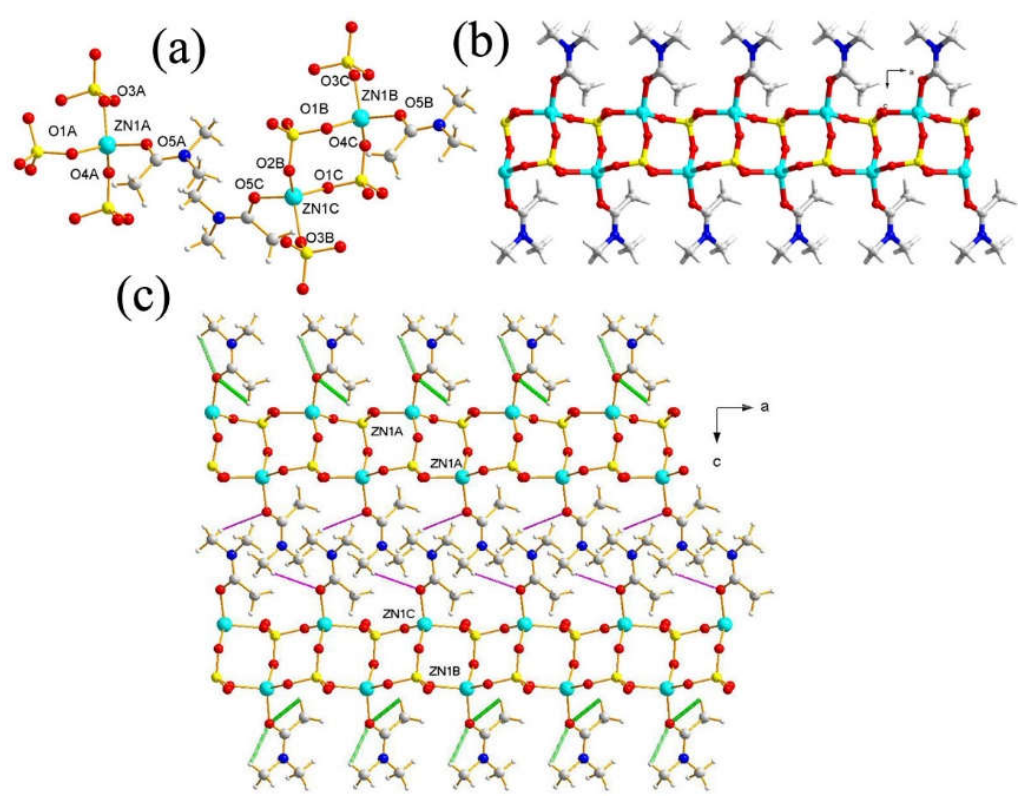

Figure 1. (a) view of the local coordination geometry of metal center and ligand (symmetric codes: A: $-\mathrm{x}+1 / 2,-\mathrm{y}, \mathrm{z}+1 / 2$; $\mathrm{B}$ : $-\mathrm{x}, \mathrm{y}+1 / 2,-\mathrm{z}+1 / 2 ; \mathrm{C}: \mathrm{x}+1 / 2,-\mathrm{y}+1 / 2,-\mathrm{z}$; (b) Packing of 1 as viewed slightly off the $b$ axis; (c) the 2D supramolecular network (the green line represents the intramolecular interactions and pink line represents the intermolecular interactions).

\section{Diffuse-reflectance UV/Vis spectroscopy}

The UV-Vis absorption spectrum of $\mathbf{1}$ in the solid state at room temperature was measured. As shown in Figure 2a, the CP1 displays one absorption band at $315 \mathrm{~nm}$, which may be ascribed to the intra-ligand charge-transfer transition (ILCT) [21]. In the diffuse reflectance spectroscopy (DRS), scattered radiation is collected and the reflected light is matching closely with the Kubelka-Munk function given by $\mathrm{F}(\mathrm{R})=(1-\mathrm{R})^{2} / 2 \mathrm{R}$, where $R$ is the reflectance at a given energy. The plot of $[\mathrm{F}(\mathrm{R}) h v]^{2} v s$ energy is presented in Figure 2b.The energy band gap $\left(E_{\mathrm{g}}\right)$ obtained by extrapolating the linear portion of the absorption edge was estimated to be $2.74 \mathrm{eV}$. The band gap of $\mathbf{1}$ indicates that it may show absorption responses to UV light and in turn may have the potential capability for catalytic photodegradation [22]. 

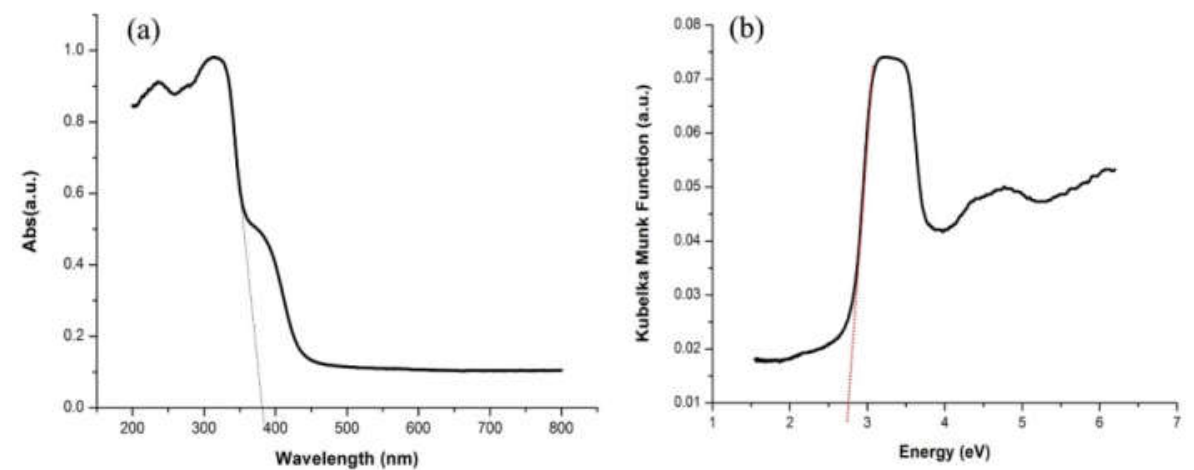

Figure 2. (a) view of the UV-Vis of $\mathbf{1}$, (b) solid-state optical diffuse-reflection spectra of $\mathbf{1}$ derived from diffuse reflectance data at ambient temperature.

\section{Photocatalysis}

The photocatalytic activity of $\mathbf{1}$ was evaluated by photo-degradation of $\mathrm{MV} / \mathrm{Rh}$ B dyes in aqueous medium. The degradation ratios of $\mathrm{MV} / \mathrm{Rh} \mathrm{B}$ dyes in water were monitored by observing the intensity of the characteristic absorption band of these dyes. No new absorption band corresponding to dyes arises in the UV-Vis absorption spectra, indicating the complete decomposition of $\mathrm{MV} / \mathrm{Rh} \mathrm{B}$ in water. In the presence of $1,47 \%$ of MV and $76 \%$ of $\mathrm{Rh} \mathrm{B}$ dyes decomposed in 80 min (Figure 3). For sake of comparison, the total catalytic degradation efficiency of the control experiment (without the use of catalyst) had also been carried out. The degradation ratio of MV and $\mathrm{RhB}$ were merely $25.2 \%$ and $18.6 \%$, respectively, in 80 min under the same condition in the absence of CP $\mathbf{1}$. These results demonstrate that the presence of $\mathbf{1}$ is necessary for the degradation of $\mathrm{MV}$ and $\mathrm{Rh} \mathrm{B}$. Also, 1 displayed better photocatalytic activity against Rh B than that of MV under similar conditions [23]. In addition, the photostability of 1 was monitored by PXRD analysis during the course of the photocatalytic reactions. The PXRD experiments confirmed that 1 can be recovered from the catalytic system and reused without obvious loss of crystallinity (as revealed by PXRD analysis) ( Figure 4).
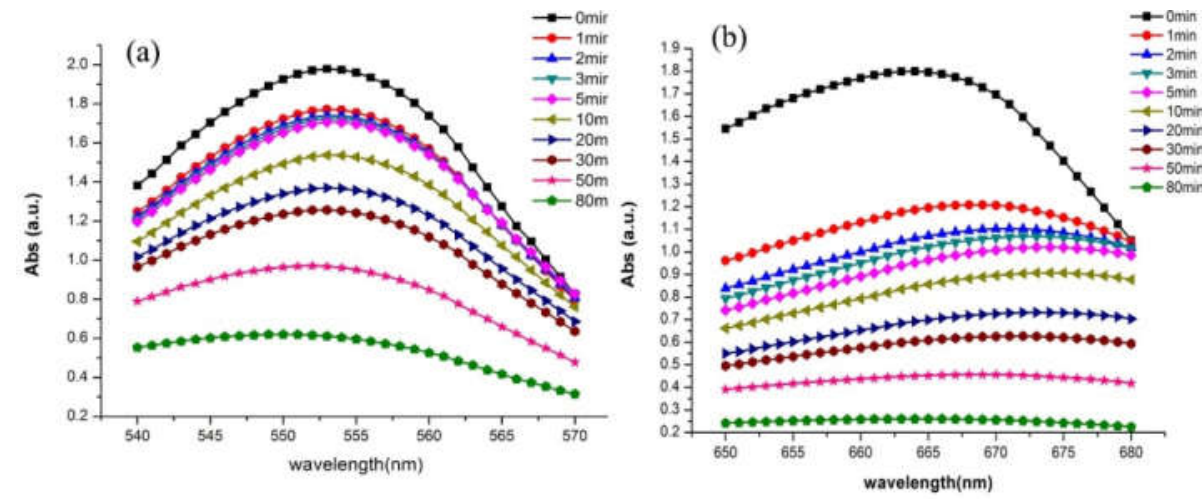

Figure 3. (a) and (b) UV-Vis absorption spectra of the MV and Rh B solution during the decomposition reaction under $250 \mathrm{~W} \mathrm{Hg}$ lamp irradiation in the presence of $\mathbf{1}$, respectively. 


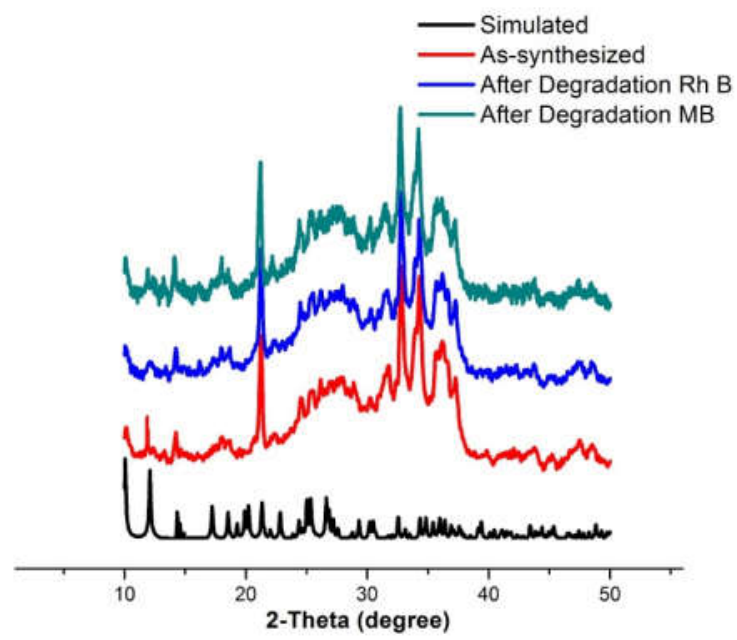

Figure 4. View of the different PXRD patterns.

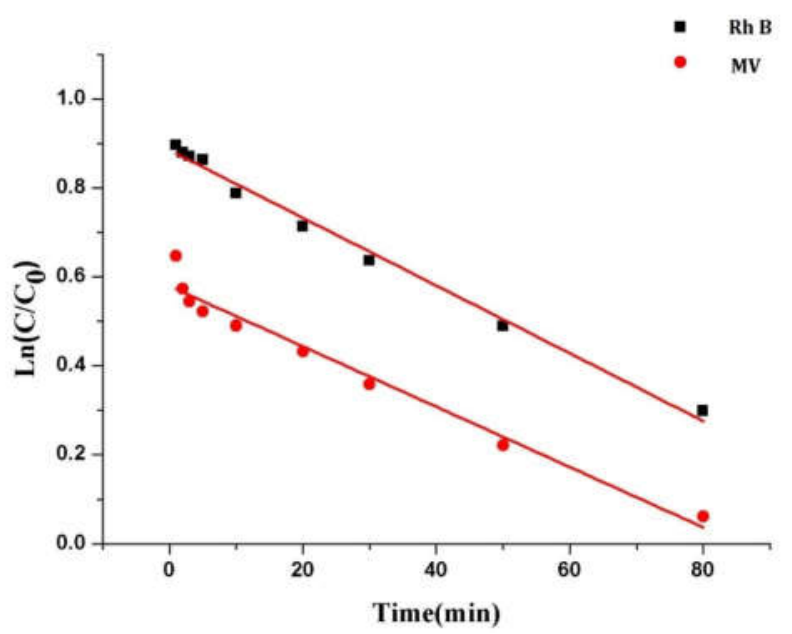

Figure 5. Langmuir-Hinshelwood plot displaying photocatalytic degradation kinetics of $\mathrm{MV} / \mathrm{Rh}$ $\mathrm{B}$ with different concentration of $\mathbf{1}$.

To investigate the kinetics of MV/Rh B photocatalytic degradation by $\mathbf{1}$, experimental data can be described by the Langmuir-Hinshelwood model as expressed by $\ln \left(C / C_{0}\right)=-k t(k=$ apparent reaction rate constant). Where $C_{0}$ is the initial concentration of $\mathrm{MV} / \mathrm{Rh} \mathrm{B}, \mathrm{t}$ is the reaction time, and $C$ is the concentration of $\mathrm{Rh} \mathrm{B} / \mathrm{MV}$ at the reaction time t. The plot of $\ln \left(C_{0} / C\right)$ and irradiation time $(\mathrm{t})$ is approximately linear and approximated the first-order kinetic equation (Figure 5). The calculated apparent rate constant $k$ values of $\mathrm{Rh} \mathrm{B}$ and $\mathrm{MV}$ are $0.761 \times 10^{-2}$ and $0.378 \times 10^{-2} \mathrm{~min}^{-1}$ for 1 , respectively. Thus, $\mathrm{Rh} \mathrm{B}$ is much higher than that of MV. Thus, 1 could be chosen as photocatalysts to degrade Rh B [24]. 
The probable mechanism associated with the photocatalytic property of $\mathbf{1}$ against organic dyes has been suggested on the basis of band structure calculations on $\mathbf{1}$ which is based on density functional theory (vide supra). The density of states (DOS) and partial DOS for $\mathbf{1}$ is presented in Figure 6 which indicates that the valence band lying just below the Fermi level is mainly contributed by the oxygen and nitrogen centers with lesser contribution by the $\mathrm{Zn}$ (II) centers. The conduction band lying just above the Fermi level in the range of -1.93 to $0.05 \mathrm{eV}$ have been derived from carbon and nitrogen, with admixture of $\mathrm{Zn}(\mathrm{II})$ centers. Therefore, the electronic transition in 1 mainly takes place from the $\mathrm{Zn}(\mathrm{II})$ center and oxygen and nitrogen region. In the typical photocatalytic process, the sample $\mathbf{1}$ may be excited to produce electronhole pairs under visible light irradiation and as band structure calculations reveal that the hole moves to $\mathrm{Zn}$ (II) centers and the electron migrates to aromatic entity. The generation of holes on the $\mathrm{d}^{10} \mathrm{Zn}(\mathrm{II})$ centers will correspond to its oxidation which is now capable to oxidize the dye to re-reduce back to $\mathrm{Zn}(\mathrm{II})$ again.

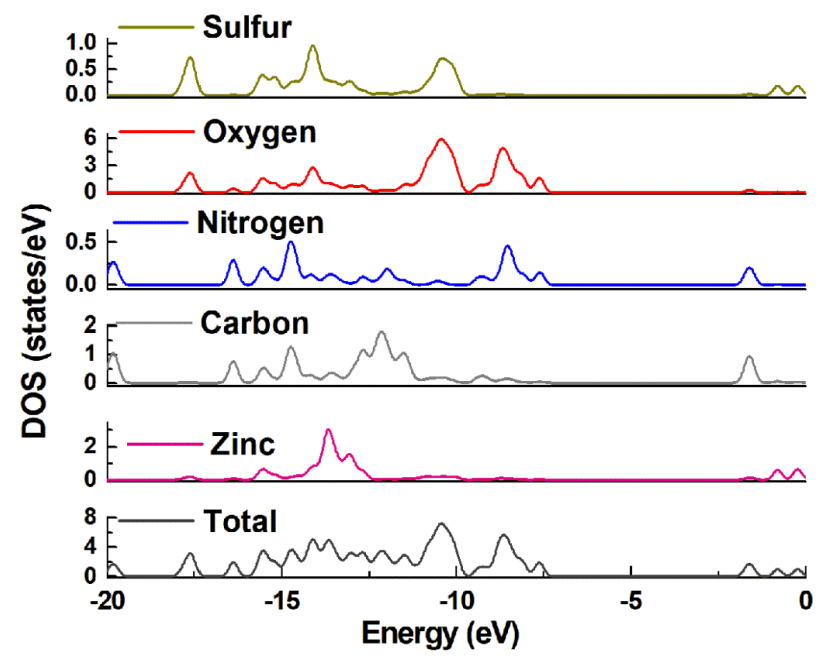

Figure 6. Total and partial DOS for CP 1.

The mechanistic scheme suggested to operate during the photocatalytic decomposition of $\mathrm{RhB} / \mathrm{MV}$ in the presence of $\mathbf{1}$ can be summarised as follows [25, 26]:

$$
\begin{aligned}
& 1 \stackrel{h v}{\longrightarrow} 1 * \text { i.e. } 1\left(\mathrm{~h}^{+}+\mathrm{e}^{-}\right) \\
& 1\left(\mathrm{~h}^{+}+\mathrm{e}^{-}\right)+\mathrm{H}_{2} \mathrm{O} \rightarrow 1\left(\mathrm{e}^{-}\right)+\mathrm{HO}+\mathrm{H}^{+} \\
& \mathrm{HO}+\mathrm{Rh} \mathrm{B} / \mathrm{MV} \rightarrow \text { oxidation products } \rightarrow \mathrm{CO}_{2}+\mathrm{H}_{2} \mathrm{O} \\
& 1\left(\mathrm{e}^{-}\right)+\mathrm{O}_{2} \rightarrow 1\left(\mathrm{O}_{2}{ }^{-}\right) \\
& \mathrm{O}_{2}{ }^{-} / \mathrm{HO}_{2}{ }^{-}+\mathrm{S} \rightarrow \text { oxidation products }
\end{aligned}
$$

1 when irradiated gets excited to generate electron-hole pair (equation 1). The reaction of the photo-excited CP 1 with water molecule (i.e. oxidative hole trapping) then generates bound 
hydroxyl $(\mathrm{OH})$ radical (equation 2). This hydroxyl radical reacts subsequently with the organic dyes viz. $\mathrm{Rh} \mathrm{B} / \mathrm{MV}$ by following different ways to produce oxidised products. The obtained oxidised products are different in Rh B (Scheme 1) [27] and MV (Scheme 2) [28]. The dioxygen behaves as an efficient oxidant for the reduced $1\left(\mathrm{e}^{-}\right)$and its key action is to regenerate the reduced photocatalyst 1 . The formation of superoxide radical anion $\mathbf{O}_{2}{ }^{-}\left(\mathrm{O}_{2}{ }^{-}+\mathbf{H}^{+} \leftrightarrow \mathbf{H O}_{2}{ }^{-}\right)$ may participate further in oxidative process.

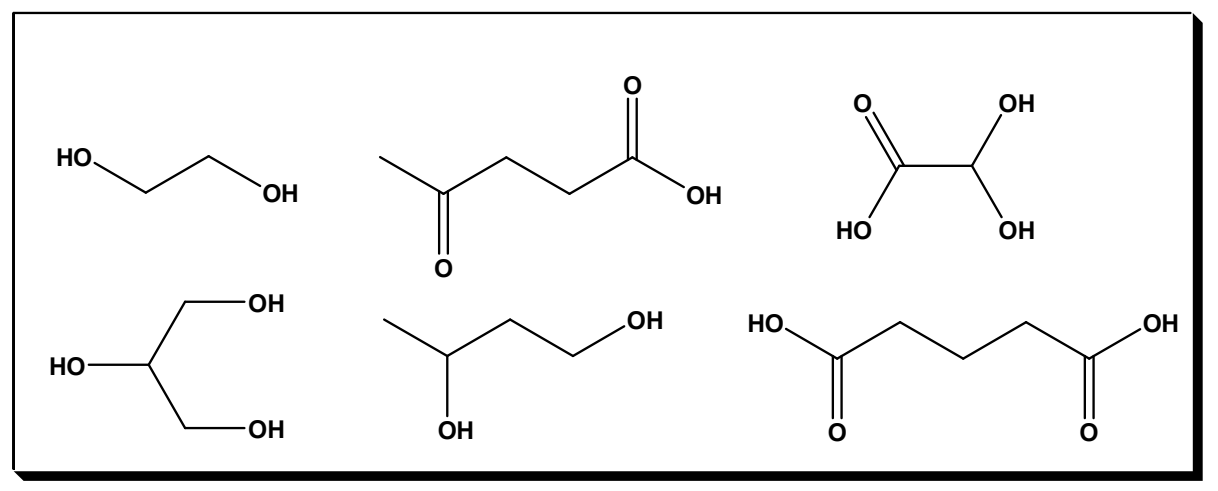

Scheme 1. The possible oxidation products obtained during the photodegradation of $\mathrm{RhB}$ in presence of 1 .

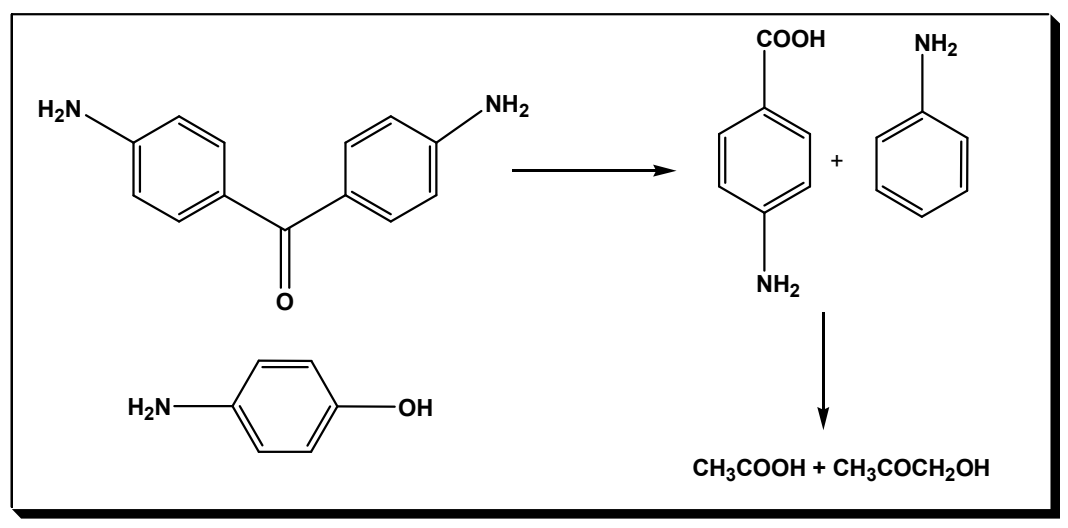

Scheme 2. The possible oxidation products obtained during the photodegradation of MV in presence of 1 .

\section{CONCLUSION}

Our results indicated that the coordination polymer $\mathbf{1}$ reported herein possesses better photocatalytic activity against $\mathrm{Rh} \mathrm{B}$. The presented investigation indicated that $\mathbf{1}$ acted as an excellent and selective adsorbent material for organic dye Rh B and can be utilized repeatedly for effective adsorption of $\mathrm{Rh} \mathrm{B}$ from waste-water without huge alleviation in the adsorption capacity. 


\section{ACKNOWLEDGEMENTS}

This work was partially supported by the grants from NSF of China (21701033), Innovative Entrepreneurial Training Plan of undergraduates in Guangdong Province (201810571008, 201810571061, 201810571047, 201810571100, 201810571101) and Innovation experiment project of Guangdong Medical University (ZYDM024), Special Funds for Scientific and Technological Innovation of undergraduates in Guangdong Province (pdjha0218, pdjha0219, pdjha0226), Featured Innovation Project of Guangdong Province (2017KTSCX083).

\section{REFERENCES}

1. Liu, L.; Ding, J.; Li, M.; Lv, X.; Wu, J.; Hou, H.; Fan, Y. Structural variability, topological analysis and photocatalytic properties of neoteric $\mathrm{Cd}(\mathrm{II})$ coordination polymers based on semirigid bis(thiazolylbenzimidazole) and different types of carboxylic acid linkers. Dalton Trans. 2014, 43, 12790-12799.

2. Li, D.; Ni, C.; Chen, M.; Dai, M.; Zhang, W.; Yan, W.; Qi, H.; Ren, Z.; Lang, J. Construction of $\mathrm{Cd}(\mathrm{II})$ coordination polymers used as catalysts for the photodegradation of organic dyes in polluted water. CrystEngComm 2014, 16, 2158-2167.

3. Jin, J.; Wu, X.; Luo, Z.; Deng, F.; Liu, J.; Singh, A.; Kumar, A. Luminescent sensing and photocatalytic degradation properties of an uncommon $(4,5,5)$-connected 3D MOF based on 3,5-di(3',5'-dicarboxylphenyl)benzoic acid. CrystEngComm 2017, 19, 4368-4377.

4. Jin, J.; Wu, J.; He, Y.; Li, B.; Liu, J.; Prasad, R.; Kumar, A.; Batten, S. A 3D luminescent $\mathrm{Zn}(\mathrm{II}) \mathrm{MOF}$ for the detection of high explosives and the degradation of organic dyes: an experimental and computational study. CrystEngComm 2017, 19, 6464-6472.

5. Shu, Z.; Jiao, X.; Chen, D. Hydrothermal synthesis and selective photocatalytic properties of tetragonal star-like $\mathrm{ZrO}_{2}$ nanostructures. CrystEngComm 2013, 15, 4288-4294.

6. Ma, L.; Abney, C.; Lin, W. Enantioselective catalysis with homochiral metal-organic frameworks. Chem. Soc. Rev. 2009, 38, 1248-1256.

7. Du, J.; Yuan, Y.; Sun, J.; Peng, F.; Jiang, X.; Qiu, L.; Xie, A.; Shen, Y.; Zhu, J. New photocatalysts based on MIL-53 metal-organic frameworks for the decolorization of methylene blue dye. J. Hazard. Mater. 2011, 190, 945-951.

8. Zhang, C.; Qiu, L.; Ke, F.; Zhu, Y.; Yuan, Y.; Xu, G.; Jiang, X. A novel magnetic recyclable photocatalyst based on a core-shell metal-organic framework $\mathrm{Fe}_{3} \mathrm{O}_{4} @ \mathrm{MIL}-100(\mathrm{Fe})$ for the decolorization of methylene blue dye. J. Mater. Chem. A 2013, 1, 14329-14334.

9. Jing, H.; Wang, C.; Zhang, Y.; Wang, P.; Li, R. Photocatalytic degradation of methylene blue in ZIF-8. RSC Adv. 2014, 4, 54454-54462.

10. Kozlova, E.; Panchenko, V.; Hasand, Z.; Khan, N.; Timofeeva, M.; Jhung, S.; Photoreactivity of metal-organic frameworks in the decolorization of methylene blue in aqueous solution. Catalysis Today 2016, 266, 136-143.

11. Lu, L.; Wang, J.; Wu, W.P.; Wu, X.R.; Kumar, A. Surface analysis and magnetism of a 1D Mn(II) complex. Bull. Chem. Soc. Ethiop. 2016, 30, 111-118.

12. Zhou, E.H,; Wang, R.; Wu, J.; Qiu, S.W.; Liu, J.Q.; Zhong, H.R.; Zeng, H.D.; Xu, J.W.; Jin, J.C. A 3D polyhedral metal-organic framework as drug carrier for controllable release. Bull. Chem. Soc. Ethiop. 2017, 31, 457-463.

13. Chu, S.; Majumdar, A. Opportunities and challenges for a sustainable energy future. Nature 2012, 488, 294-303.

14. Alvaro, M.; Carbonell, E.; Ferrer B.; Xamena, F.; Garcia, H. Semiconductor behavior of a metal - organic framework (MOF). Chem. Eur. J. 2007, 13, 5106-5112.

15. Sheldrick, G. SHELXT - Integrated space-group and crystal-structure determination. Acta Crystallogr., Sect. A: Found. Adv. 2015, 71, 3-8.

16. Frisch, M.J.; Trucks, G.W.; Schlegel, H.B.; Scuseria, G.E.; Robb, M.A.; Cheeseman, J.R.; Montgomery, J.A.; Vreven Jr., T.; Kudin, K.N.; Burant, J.C.; Millam, J.M.; Iyengar, S.S.; Tomasi, J.; Barone, V.; Mennucci, B.; Cossi, M.; Scalmani, G.; Rega, N.; Petersson, G.A.; Nakatsuji, H.; Hada, M.; Ehara, M.; Toyota, K.; Fukuda, R.; Hasegawa, J.; Ishida, M.; 
Nakajima, T.; Honda, Y.; Kitao, O.; Nakai, H.; Klene, M.; Li, X.; Knox, J.E.; Hratchian, H.P.; Cross, J.B.; Bakken, V.; Adamo, C.; Jaramillo, J.; Gomperts, R.; Stratmann, R.E.; Yazyev, O.; Austin, A.J.; Cammi, R.; Pomelli, C.; Ochterski, J.W.; Ayala, P.Y.; Morokuma, K.; Voth, G.A.; Salvador, P.; Dannenberg, J.J.; Zakrzewski, V.G.; Dapprich, S.; Daniels, A.D.; Strain, M.C.; Farkas, O.; Malick, D.K.; Rabuck, A.D.; Raghavachari, K.; Foresman, J.B.; Ortiz, J.V.; Cui, Q.; Baboul, A.G.; Clifford, S.; Cioslowski, J.; Stefanov, B.B.; Liu, G.; Liashenko, A.; Piskorz, P.; Komaromi, I.; Martin, R.L.; Fox, D.J.; Keith ,T.; Al-Laham, M.A.; Peng, C.Y.; Nanayakkara, A.; Challacombe, M.P.; Gill, M.W.; Johnson, B.; Chen, W.; Wong, W.M.; Gonzalez, C.; Pople, J.A. Gaussian, Inc.: Wallingford CT; 2009.

17. O'Boyle, N.; Tenderholt, A.; Langner, K. CCLIB: A library for package - independent computational chemistry algorithms. J. Comp. Chem. 2008, 29, 839-845.

18. Lu, L.; Wu, J.; Wang, J.; Liu, J.; Li, B.; Singh, A.; Kumar, A.; Batten, S. An uncommon 3D 3,3,4,8-c Cd(II) metal-organic framework for highly efficient luminescent sensing and organic dye adsorption: experimental and theoretical insight. CrystEngComm. 2017, 19, 7057-7067.

19. Zhou, E.; Li, B.; Chen, W.; Luo, Z.; Liu, J.; Singh, A.; Kumar.; Jin, J. Photocatalytic degradation of organic dyes by a stable and biocompatible $\mathrm{Zn}$ (II) MOF having ferulic acid: Experimental findings and theoretical correlation. J. Mol. Struct. 2017, 1149, 352-356.

20. Wu, W.; Li, B.; Gu, C.; Wang, J.; Singh, A.; Kumar, A. Luminescent sensing of $\mathrm{Cu}^{2+}$, $\mathrm{CrO}_{4}{ }^{2-}$ and photocatalytic degradation of methyl violet by $\mathrm{Zn}(\mathrm{II})$ metal-organic framework (MOF) having 5,5'-(1H-2,3,5-triazole-1,4-diyl)diisophthalic acid ligand. J. Mol. Struct. 2017, 1148, 531-536.

21. Lu, L.; Wang, J.; Cai, S.; Xie, B.; Li, B.; Man, J.; He, Y.; Singh, A.; Kumar, A. Efficient photocatalytic degradation of methyl violet with two metall-organic frameworks. J. Coord. Chem. 2017, 70, 3409-3421.

22. Censo, D.; Fantacci, S.; Angelis, F.; Klein,C.; Evans, N.; Kalyanasundaram, K.; Bolink, H.; Grätzel, M.; Nazeeruddin, M. Synthesis, characterization, and mDFT/TD-DFT calculations of highly phosphorescent blue light-emitting anionic iridium complexes. Inorg. Chem. 2008, 47, 980-989.

23. Wang, L.; Noh, H.; Moon, B.; Park, S.; Kim, K.; Shi, J.; Jeong, J. Dual-mode luminescence with broad near UV and blue excitation band from $\mathrm{Sr}_{2} \mathrm{CaMoO6}: \mathrm{Sm}^{3+}$ phosphor for white LEDs. J. Phys. Chem. C 2015, 119, 15517-15525.

24. Li, D.; Ni, C.; Chen, M.; Dai, M.; Zhang, W.; Yan, W.; Qi, H.; Ren, Z.; Lang, J. Construction of $\mathrm{Cd}(\mathrm{II})$ coordination polymers used as catalysts for the photodegradation of organic dyes in polluted water. CrystEngComm. 2014, 16, 2158-2167.

25. Silva, C.; Corma, A.; García, H. Metal-organic frameworks as semiconductors. J. Mater. Chem. 2010, 20, 3141-3156.

26. Cheng, H.; Tang, H.; Shen, Y.; Xia, N.; Yin, W.; Zhu, W.; Tang, X.; Ma, Y.; Yuan, R. Carboxylate ligands induced structural diversity of zinc(II) coordination polymers based on 3,6-bis(imidazol-1-yl)carbazole: Syntheses, structures and photocatalytic properties. J. Solid State Chem. 2015, 232, 200-206.

27. Barras, A.; Cordier, S.; Boukherroub, R. Fast photocatalytic degradation of rhodamine B over $\left[\mathrm{Mo}_{\mathrm{BBr}}\left(\mathrm{N}_{3}\right)_{6}\right]^{2-}$ cluster units under sun light irradiation. Appl. Catal., B 2012, 123-124, $1-8$.

28. Wu, J.; Li, B.; Zhong, H.; Qiu, S.; Liang, Y.; Zhuang, X.; Singh, A.; Kumar, A. Fluorescence sensing and photocatalytic properties of a 2D stable and biocompatible Zn(II)based polymer. J. Mol. Struct. 2018, 1158, 264-270.

29. Yu, K.; Yang, S.; He, H.; Sun, C.; Gu, C.; Ju, Y. Visible light-driven photocatalytic degradation of Rhodamine $\mathrm{B}$ over $\mathrm{NaBiO}_{3}$ : Pathways and mechanism. J. Phys. Chem. A 2009, 113, 10024-10032.

30. Sinha, T.; Ahmaruzzaman, M. Photocatalytic decomposition behavior and reaction pathways of organic compounds using $\mathrm{Cu}$ nanoparticles synthesized via a green route. Photochem. Photobiol. Sci. 2016, 15, 1272-1281. 